ISAHP 2001, Berne, Switzerland, August 2-4, 2001

\title{
EVALUATION OF CONSTRUCTIVE SOLUTIONS FOR SUPPORTS OF TELECOMMUNICATION EQUIPMENT HOUSINGS
}

\author{
Pablo Aragonés, Juan Pastor, Mónica García \\ Department of Engineering Design and Project Management \\ Universidad Politécnica de Valencia \\ Camino de Vera s/n 46022 Valencia - Spain \\ www.dpi.upv.es \\ aragones@dpi.upv.es \\ jppastor@dpi.upv.es \\ mcgarciam@dpi.upv.es \\ Arturo Martí \\ Ingeniería 10 S.A.L. \\ Gran Vía Marques del Turia, № 49 - 46005 Valencia - Spain \\ www.ingenieria10.es \\ amc@,ingenieria10.es
}

Keywords: project management, technology, engineering

Summary: During the start-up phase of a new mobile telephone company it needs to install its own GSM network, satisfying previously established schedules, standards and budgets. The case studied in the present paper consists in the evaluation of possible constructive solutions for the supports of the cabinets housing of the telecommunication equipment on roof-tops of buildings. Although the cost of these supports is relatively low compared to that of the overall installation, the choice of support basically has an impact on the construction time and commissioning.

These supports have been traditionally built from steel beams. The study carried out covers four possible solutions: three of them use steel beams, while the fourth alternative uses fibro-plastic (FRP) beams. These have the advantages of being very resistant, they can be machined on site and they have such light weight that a single operator can carry them.

In order to convince the GSM operator and the start-up contractor of which is the best choice, an evaluation study of the constructive solutions has been carried out using Multicriteria Decision Aid Techniques. The Analytical Hierarchy Process (AHP) of Saaty has been followed. These techniques have the advantage of taking into account different criteria and points of view to analyse the problem and balance out the interests of all parties involved in the final decision.

The present paper describes the choice process followed and the solutions reached, and includes a sensitivity analysis which allows modifications to the weighting of the various criteria considering the interests of the operator and the start-up contractor 


\section{INTRODUCTION}

In this paper, we present a decision-making problem, solved by the method AHP and the software Expert Choice. The background of the problem is the Project Management. In this case, the constructive solutions for the supports of the cabinets housing of the telecommunication equipment on roof-tops of buildings for a GSM net must be chosen. This decision may seem simple if we think in all the decision problems involved in the implantation of a new company but, the success in this problem can decrease the execution time-limits, allowing to give service to the customers as soon as possible. This application can be used as an example of the utility of decision aid techniques, especially the AHP method, to the project managers.

\section{DECISION PROBLEM}

The decision problem context is the following: in Spain there are two companies awardees of concessions of GSM telephony. The Spanish government has adjudicated a third license to Amena Inc. This company must get ready its own net as soon as possible, in order to compete against the already established companies. The constructor company is Siemens. Third actor in the problem is the engineering company, Ingeniería 10, that accomplishes a technical consultantship labour for both companies.

Then, the engineering company must advise how to construct the stone benches. After a technical study, the engineering company finded four possible solutions: to build the stone bench with beams of continuous steel, with beams of cut steel, with beams of steel in spider, three traditional constructive solutions, or with beams of fibro-plastic.

To solve this problem, Ingeniería 10 asked the Department of Engineering Design and Project Management of the Polytechnical University of Valencia (UPV) for advise, to priorice the alternatives, taking into account the priorities of both parts: the telephone company of and the construction firm.

What the customer wanted was very clear: to order the four constructive alternatives. From the technical point of view, the engineering advisor knows the response of the materials, and the advantadges and inconveniences of every solution. Its problem is to add these judgments and to do it taking into account both parts. The construction firm is interested in the faster solution to construct, to be able to accomplish the deadline fixed in the contract with the telephone company. On the other hand, the telephone firm considers that the execution time-limit is guaranteed by means of the contract, and the solution must satisfy it long-term benefits. Construction costs are important for both companies.

\section{METHODOLOGY}

The team of the Polytechnical University of Valencia, proposed the following steps to order the alternatives: 


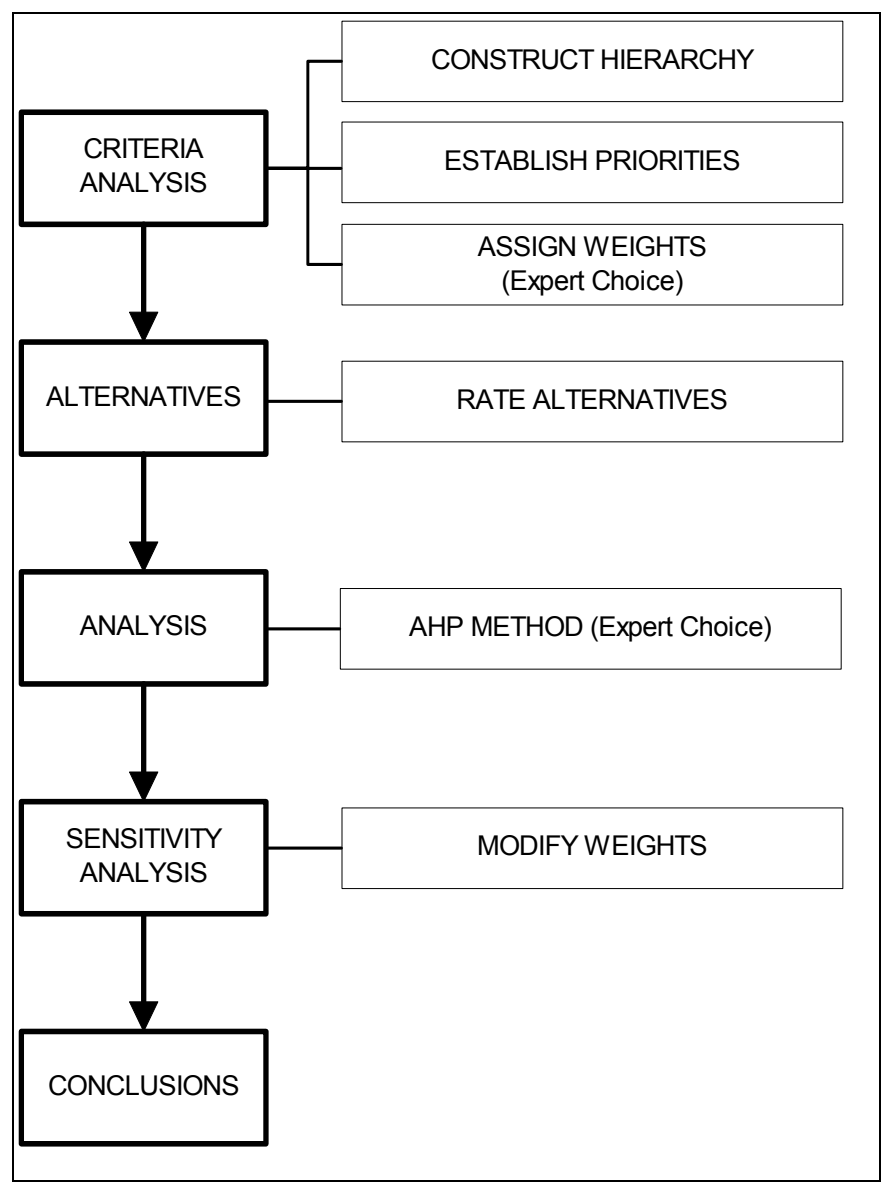

Figure 1.- Proposed steps.

Phase 1. Criteria analysis. In the first place, after several work meetings, the decision criteria were established. This phase was splited in three stages:

a) Settling a hierarchy. The global objective was broken down inTO partial objectives to get to the final criteria. The alternatives were evaluated upon these final criteria.

b) After, the priorities among the criteria were established following the comparison method AHP, in each hierarchic level.

c) By means of the program of support Expert Choice, following the method AHP, the weights or the importance degrees were obtained.

Phase 2. Alternatives evaluation. The evaluation of every alternative took place in a reassembly. A qualitative scale was settled for each criterion to evaluate the alternatives. The evaluation came true according to the technical experience professional of the advisor D. Arthur Martí of Ingeniería 10.

Phase 3. Analysis. Ordering the alternatives from the evaluation matrix obtained in the previous phase. This ordering was reached true following the method AHP.

Phase 4. Sensitivity analysis. This analysis is necessary to study the influence of variations in the criteria weights in the results, taking into account the possible imprecision in criteria comparisons. The software Expert Choice allows a dynamic modification of the weights in each hierarchic level.

Phase 5. Conclusions. In this phase, the final conclusions were obtained and presented to the stakeholders. 


\section{CRITERIA HIERARCHY}

To establish the criteria structure, several meetings among Ingeniería 10 engineers and the aid decision group were accomplished. The final criteria tree had four levels. The hierarchy was structured in short-term criteria and long-term criteria. The resulting criteria and the hierarchy are showed below.

1. SHORT TERM. Criteria that have influence in the process of the cabinet housing installation.

2. DEADLINE. This criteria takes into account the influence of each constructive solution in the execution deadline of the host station net.

3. AVAILAB. It analyses for each alternative the availability of the material in a determined time-limit.

4. PROCESS. Takes into account the influence in the time-limit of the previous material process for each alternative.

5. COMPLEX. Constructive complexity of every solution.

6. COST. The price of the alternative.

7. INSITU. The costs of every alternative at the site.

8. ELEVATION. The elevation costs of the materials from bottom to top for each alternative.

9. ASSEMBLY. This criterion considers the installation and set-up costs out of every solution.

10. PROCOST. The costs of the previous treatments of the materials.

11. NORM. Criteria that takes into account if the alternative accomplishes the construction ground norms.

12. SFH. Safety and health level during the construction cabinet housing supports.

13. ADJUST. This criterion analyses the adjusting out of every alternative to the technical specifications.

14. STRENGTH. The resistance of the alternative materials.

15. LOADSTR. It considers if the alternative transmits adequately the loads to the building.

16. WARPING. It studies the displacement of every solution.

17. CONDUCT. It analyses the conductivity.

18. WOBBLE. The oscillation of the cabinet after construction, when there are workers inside it.

19. LONG TERM. Criteria that have influence during the use of the host station.

20. MAINTEN. It takes into account the maintenance costs during the use of the host station.

21. VANDAL. Possible vulnerability of every alternative in front of vandal or sabotage situations.

22. PERFMAT. Long-term performance of the material.

23. FIRE. Fire-resistance performance.

24. THERMAL. Performance of the solution to heat loads.

25. CORROSION.

26. IMPACT. Accidental impact resistance. 


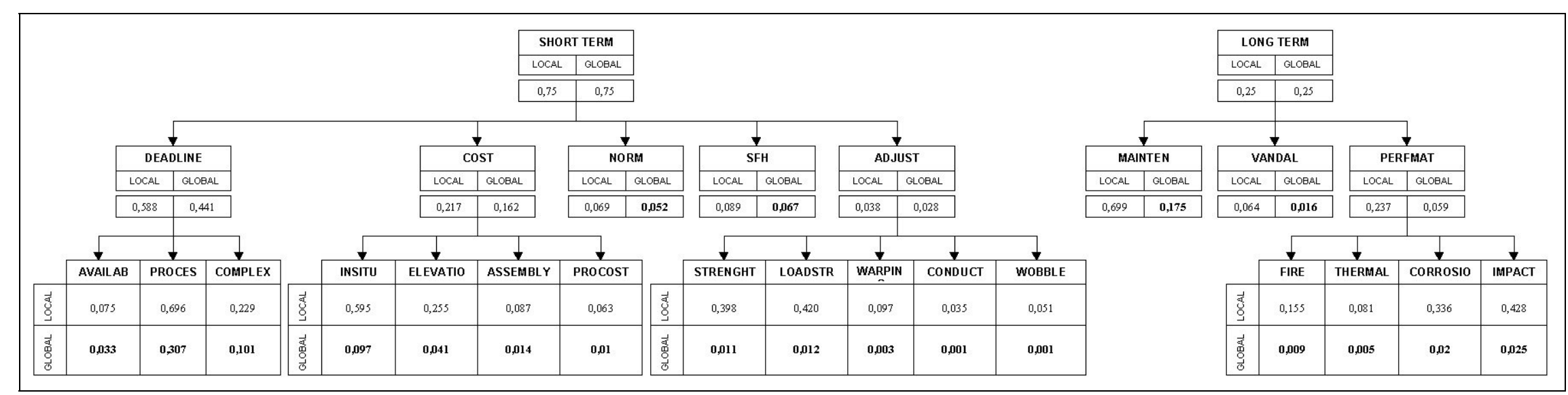

Figure 2.- Criteria hierarchy and initial weights.

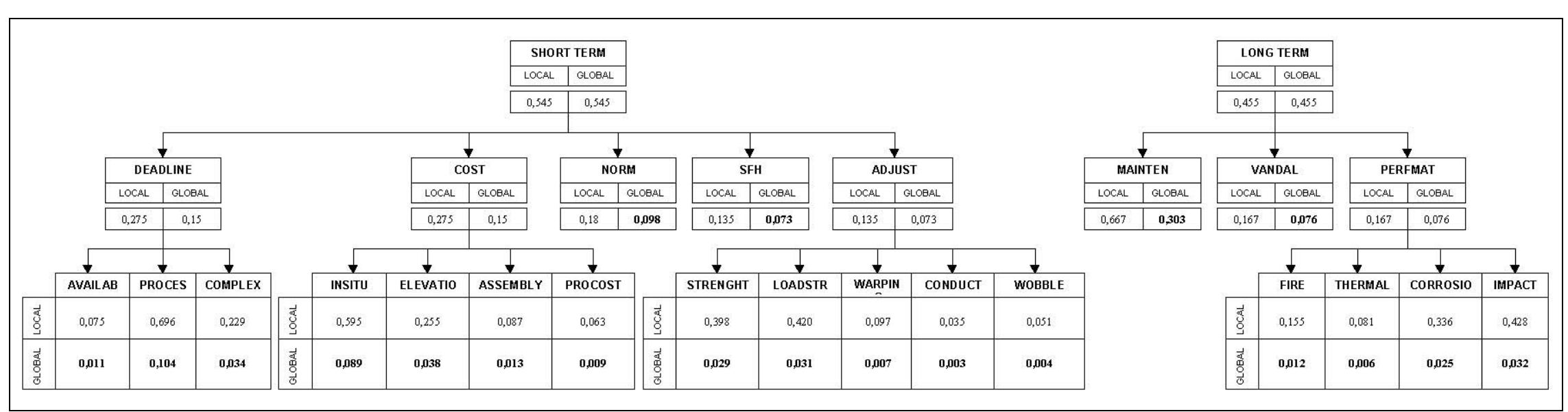

Figure 3.- GSM firm weights. 


\section{ALTERNATIVES RATING}

We present the four alternatives of the problem, with a brief description in the following table.

\begin{tabular}{|l|l|l|}
\hline \multicolumn{1}{|c|}{ ABREVIATTION } & \multicolumn{1}{|c|}{ ALTERNATIVE } & \multicolumn{1}{c|}{ DESCRIPTION } \\
\hline ACECONT & Steel stone bench continuous. & $\begin{array}{l}\text { Steel beams cut according to the distance } \\
\text { among pillars and galvanized afterwards. }\end{array}$ \\
\hline ACEPART & Steel stone bench cut. & $\begin{array}{l}\text { Steel beams with standardized length, } \\
\text { galvanized and assembled on site. }\end{array}$ \\
\hline FRP & Fibro-plastic stone bench & $\begin{array}{l}\text { FRP's beams that do not need previous } \\
\text { process, lightweight, they can be cut easily on } \\
\text { site. }\end{array}$ \\
\hline ACEARAÑA & Steel spider type stone bench & $\begin{array}{l}\text { Steel beams of standardized length, with } \\
\text { multiple supports on the flat roof. }\end{array}$ \\
\hline
\end{tabular}

Table 1.- Alternatives descriptions.

The following step in the process is the alternative evaluation for all decision criteria. Establishing accurate and objective quantitative values for every alternative according to each criterion, required to arrange detailed projects for each constructive solution. However, this was not possible because of time. Although this studies were available, some criteria could not be quantitative evaluated, because they needed qualitative assessment. Therefore, the Ingeniería 10 engineers and the UPV decision facilitators, chose to evaluate qualitatively each alternative according to each opinion, on the basis of the technical experience of the advisor D. Arthur Martí of Inc. Ingeniería 10. Due to the little time availability of the expert, it was agreed to use an evaluation scale instead of binary comparisons. In a specific evaluation meeting, evaluation scale of 1 to 9 with intermediate judgments was established. In all the cases, the scale was defined to maximize the criteria, that is, the best alternative from the point of view of the expert could obtain 9 points over 9 and the worse one could only obtain 1 .

Bellow, as an example, a table with the scale definition and the alternatives evaluation results for the criteria AVAILAB is shown.

\begin{tabular}{|c|c|}
\hline \multicolumn{2}{|c|}{$\begin{array}{l}\text { Material available in a fixed term. To imported materials, this } \\
\text { criteria means that the material is available in stock. } \\
\text { What matters in this case is the time between two transports, } \\
\text { in order to have always material available in stock. }\end{array}$} \\
\hline LABEL & VALUE \\
\hline Material is available in optimum term, 5 days. & 9 \\
\hline Material is available in short term, lower medium time limit average. & 7 \\
\hline Material is available in middle term (20-30 days). & 5 \\
\hline Material is available in mediocre term, above average. & 3 \\
\hline Material is available in too long time. & 1 \\
\hline ALTERNATIVES & ASSESMENT \\
\hline ACECONT & 9 \\
\hline ACEPART & 9 \\
\hline FRP & 5 \\
\hline ACEARAÑA & 9 \\
\hline
\end{tabular}

Table 2.- Evaluation target. 


\section{INITIAL RESULTS}

After introducing all data in Expert Choice software, the following results were obtained:

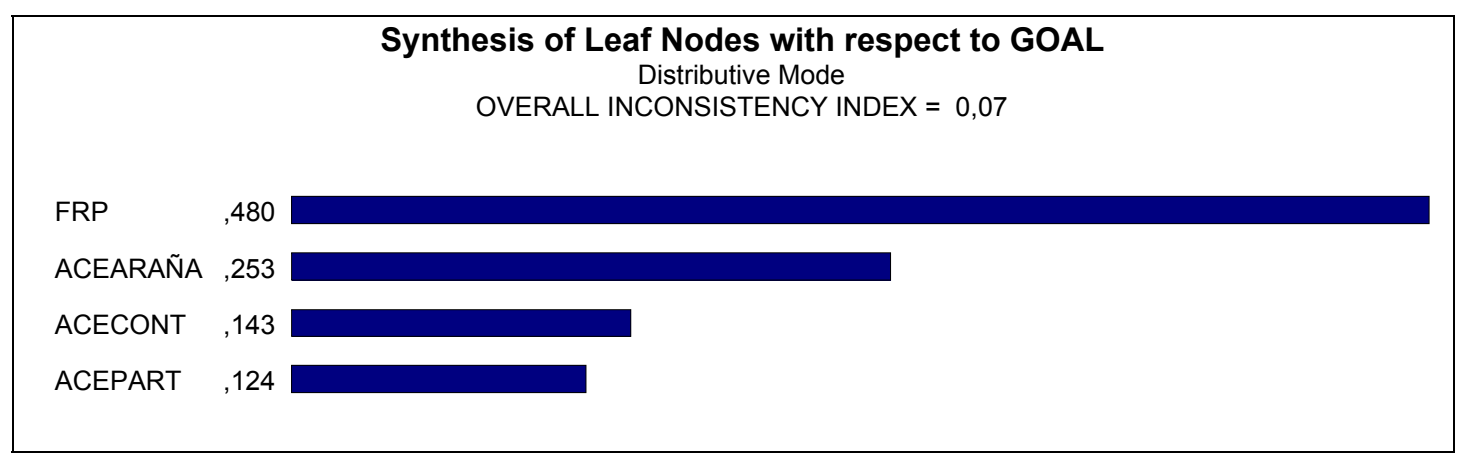

Figure 4.- Initial results.

\section{SENSITIVITY ANALYSIS: MODIFYING WEIGHTS}

In the previous analysis, the short term criteria were considered very important, as well as deadline and cost. This scenario can be interesting from the contractor's point of view, who has to deliver the host stations in already specified dates and costs. Evidently, the proprietary company of the net will be interested in the fulfilment of the contract order.

However, another possible scenario could be that the time-limit and the cost are guaranteed by contract, therefore the company's criteria can be orientated towards the consideration that the fulfilment of the ground rules (NORM), safety and health (SFH), technical adjusting (ADJUST) and long term criteria have bigger importance.

For this reason a new scenario was studied, with the following weights: cost and deadline $15 \%$ each one, NORM $10 \%$, SFH, ADJUST, VANDAL and PERFMAT 7,5\% everyone, and 30\% maintenance cost. Finally, cost and deadline criteria which fulfilment is guaranteed by contract would weigh $30 \%$ (instead of previous $60 \%$ ). The rest of the criteria, more important from the company's point of view, have now an importance of $70 \%$ (instead of previous $40 \%$ ). Figure 3 shows this reappraisal. New results were very similar to previous ones.

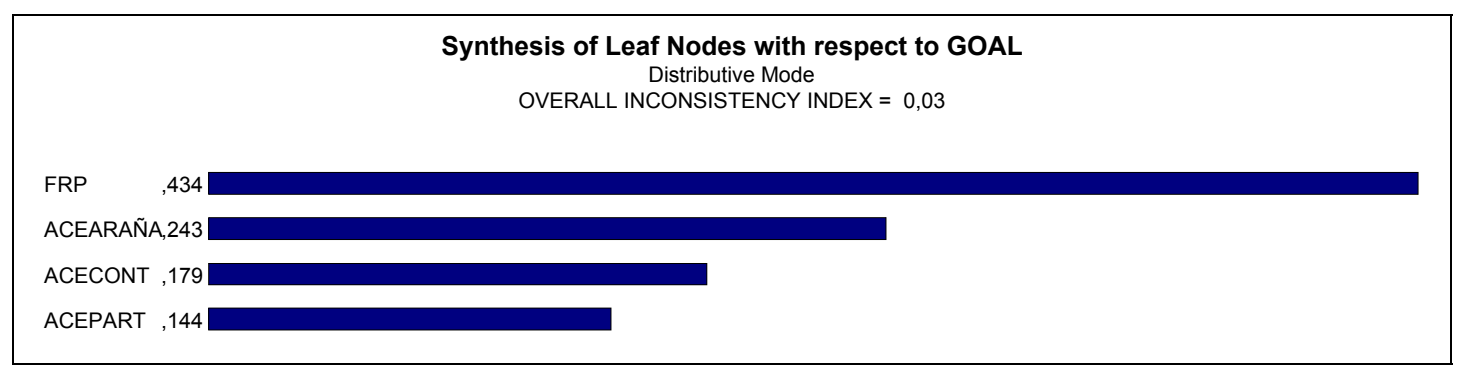

Figure 5.- Results with modified weights 


\section{CONCLUSIONS}

Decision aid methods are a very useful tool in any context of the engineering, particularly in the Project Management. In our opinion, the main contribution of these techniques is not only the final result, but also the analysis and the careful consideration of the problem, needed to construct the classical evaluation matrix. For this analysis, the method AHP along with the program Expert Choice, have shown their validity to elaborate the criteria hierarchy.

According to our experience in aid decision consultantship in projects, the assessor (working as a middleman) must serve as link between the methods and the decision maker. The decision maker and all the people who take part in the decision process, are usually very busy at their job and with a scarce availability of time. For this reason, the adviser must explain the decision process and explain the techniques with a language that the decision maker could be able to understand, and must prepare the necessary documents to pick up the information in a fast and easy way. If the decision maker understands the process, his information (priorities, opinions, arguments, ...) will be clearer, useful and truthful, increasing the reliability of the decision.

Another aspect that we consider very important is the sensitivity analysis. Although the decision maker understands the decision process and he knows, in a general way, the decision method, he needs a reinforcement in the confidence of the results. This reinforcement, must come from sensitivity analysis that shows the results variations in front of his information changes. At this point, Expert Choice software is useful and easy-to-use.

\section{REFERENCES}

Saaty, T.L. (1994) Fundamentals of Decision Making and Priority Theory with the Analytic Hierarchy Process, Pittsburgh: RWS Publications.

Saaty, T.L. (1996) Multicriteria Decision Making: The Analytic Hierarchy Process, Pittsburgh: RWS Publications. 